九州大学学術情報リポジトリ

Kyushu University Institutional Repository

\title{
High-pressure torsion for enhanced atomic diffusion and promoting solid-state reactions in the aluminum-copper system
}

Oh-ishi, Keiichiro

National Institute for Materials Science

Edalati, Kaveh

Department of Materials Science and Engineering, Faculty of Engineering, Kyushu University | WPI, International Institute for Carbon-Neutral Energy Research (WPI-I2CNER), Kyushu University

Kim, Hyoung Seop

Department of Materials Science and Engineering, Pohang University of Science and Technology

Hono, Kazuhiro

National Institute for Materials Science

他

ht tp://hdl. handle. net/2324/26385

出版情報: Acta Materialia. 61 (9)，pp.3482-3489，2013-03. Elsevier バージョン：

権利関係 : (C) 2013 Acta Materialia Inc. 


\title{
High-pressure torsion for enhanced atomic diffusion and promoting solid-state reactions in the aluminum-copper system
}

\author{
Keiichiro Oh-ishi $^{\text {a }}$, Kaveh Edalati ${ }^{\text {b,c,*, Hyoung Seop Kim }}{ }^{\text {d }}$, Kazuhiro Hono ${ }^{\text {a }}$, \\ Zenji Horita ${ }^{\text {b,c }}$
}

a National Institute for Materials Science, 1-2-1 Sengen, Tsukuba 305-0047, Japan

${ }^{\mathrm{b}}$ Department of Materials Science and Engineering, Faculty of Engineering, Kyushu University, Fukuoka 819-0395, Japan

c WPI, International Institute for Carbon-Neutral Energy Research (WPI-I2CNER), Kyushu University, Fukuoka 819-0395, Japan

${ }^{\mathrm{d}}$ Department of Materials Science and Engineering, Pohang University of Science and Technology, Pohang 790-784, Republic of Korea

\begin{abstract}
This study reports that solid-state reactions occur by the application of high-pressure torsion (HPT) to the $\mathrm{Al}-\mathrm{Cu}$ system even at low homologous temperature. A bulk form of disc consisting of two separate half-discs of pure $\mathrm{Al}$ and pure $\mathrm{Cu}$ are processed by HPT at ambient temperature under a pressure of $6 \mathrm{GPa}$. X-ray diffraction analysis and high-resolution transmission electron microscopy confirm the formation of different intermetallic phases such as $\mathrm{Al}_{2} \mathrm{Cu}, \mathrm{AlCu}$ and $\mathrm{Al}_{4} \mathrm{Cu}_{9}$, as well as the dissolution and supersaturation of $\mathrm{Al}$ and $\mathrm{Cu}$ in each matrix. It is shown that the diffusion coefficient is enhanced by $10^{12}-10^{22}$ times during the HPT processing in comparison with the lattice diffusion and becomes comparable to the surface diffusion. The enhanced diffusion is attributed to the presence of a high density of lattice defects such as vacancies, dislocations and grain boundaries produced by HPT processing.
\end{abstract}

Keywords: Severe plastic deformation (SPD); Intermetallics; Ultrafine grains; Diffusion coefficient; Phase transformation

* Corresponding author at: Department of Materials Science and Engineering, Faculty of Engineering, Kyushu University, Fukuoka 819-0395, Japan. Tel./fax: +81 928022992.

E-mail address: Kaveh.edalati@zaiko6.zaiko.kyushu-u.ac.jp (K. Edalati). 


\section{Introduction}

There are several processing methods to achieve solid-state reactions in metallic systems such as diffusion bonding, mechanical milling of elemental powders, rolling and folding of laminated thin layers, drawing or extrusion of banded fibrous wires, and so on [1]. The solid-state reactions can be promoted by increasing temperature and/or by imposing intense plastic strain, and thus both attempts enable the reactions faster in bulk forms [1]. In particular, severe plastic deformation (SPD) is gaining much attention in these days because it can attain not only significant grain refinement of bulk metallic materials [2] but also consolidation and bonding of metallic powders [3], composites [4] and machining chips [5] at ambient temperatures without the conventional sintering process.

Typical processes of SPD include equal-channel angular pressing (ECAP), accumulative-roll bonding (ARB) and high-pressure torsion (HPT) [6]. Solid-state alloying was then achieved with such processes in different metallic systems: $\mathrm{Al}-\mathrm{Cu}$ [7], $\mathrm{Al}-\mathrm{Zn}-\mathrm{Mg}-\mathrm{Cu}$ [8] and $\mathrm{Cu}-\mathrm{Cr}-\mathrm{Ag}$ [9] by ECAP; Cu-Ag [10] and Cu-Zr [10] by ARB, Al-Mg [11], Al-W [12,13], Cu-Ag [14], Cu-Ni [15], $\mathrm{Cu}-\mathrm{Cr}$ [16], Cu-Co [17], Cu-Fe [17], Cu-W [18], W-Ti [13] and W-Ni [13] and Ni-Al-Cr [19] by HPT.

Among various SPD processes, HPT may be the most unique process [20]. It provides grain refinement of hard-to-deform materials such as $\mathrm{W}$ [21] and intermetallics [22] and induces phase transformation because of high pressure [23] or high strain [24]. Furthermore, solid-state reactions can be achieved with HPT: amorphization in $\mathrm{Cu}-\mathrm{Zr}$ [25], $\mathrm{Cu}-\mathrm{Ag}$ [25], $\mathrm{Cu}-\mathrm{Zr}-\mathrm{Ti}$ [26] and Ni-Ti [27], intermetallics formation in Al-Mg [11], Al-Ni [28] and Al-Ti [29], carbide formation in $\mathrm{Cu}-\mathrm{Nb}-\mathrm{C}$ [30] and hydride formation in Hf-H [31].

In this study, HPT is applied to a bulk form of discs in the Al-Cu system at ambient temperature and it is demonstrated that solid-state reactions well undergo-during the HPT operation because of unusually enhanced lattice diffusion.

\section{Experimental procedures}

Rods of $10 \mathrm{~mm}$ in diameter were prepared from high purity $\mathrm{Al}$ (99.99\%) and $\mathrm{Cu}$ (99.96\%). They were annealed for 1 hour at $773 \mathrm{~K}$ for $\mathrm{Al}$ and at $873 \mathrm{~K}$ for $\mathrm{Cu}$. Each rod was cut into two halves along the longitudinal axis using a wire cutting electrical discharge machine. The half-rods were sliced to the thicknesses of $0.8 \mathrm{~mm}$. One half disc of $\mathrm{Al}$ and one half disc of $\mathrm{Cu}$ were placed together in a circular shallow hole of the lower HPT anvil, as shown in Fig. 1(a). The lower anvil was then raised to contact with the upper anvil having the same shallow hole at the center. While applying a pressure of $6 \mathrm{GPa}$ at room temperature, both anvils were rotated with respect to each other at a rotation speed of $1 \mathrm{rpm}$ and the rotation was terminated after either 1, 10 or 100 turns. The appearance of a sample before HPT and after 100 turns was shown in Fig. 1(b). The temperature during HPT operation was measured using a thermocouple placed $10 \mathrm{~mm}$ away from the bottom surface of the upper shallow hole. The temperature reached $~ 333 \mathrm{~K}$ during HPT operation after 100 turns. Details concerning the temperatures rise during HPT was given in earlier papers [32,33]. The HPT-processed discs were first examined by X-ray diffraction (XRD) analysis using the Co Ka 
radiation at a scanning speed of $0.2-0.4 \% \mathrm{~min}$ and a step interval of $0.01^{\circ}$.
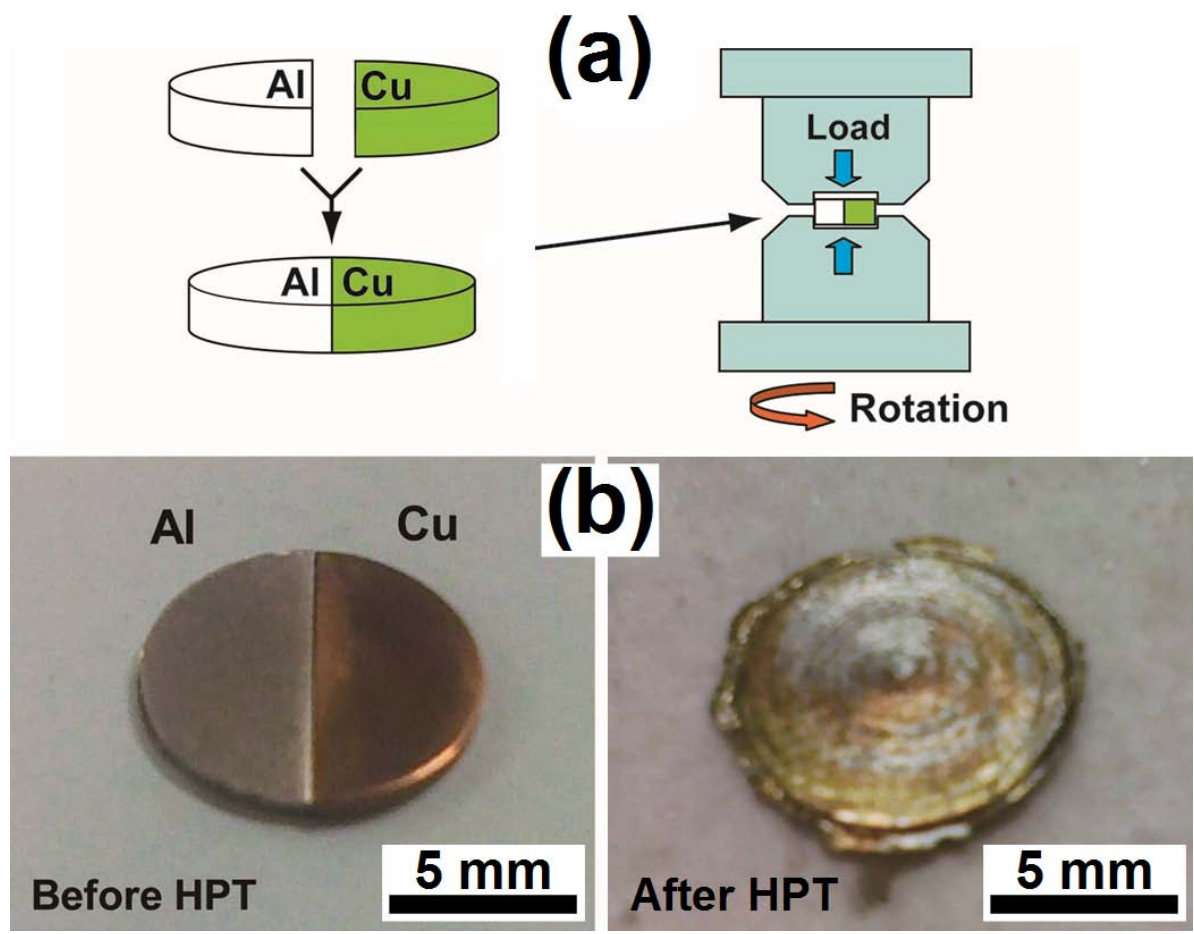

Figure 1. (a) Schematic illustration of HPT processing and (b) appearance of Al-Cu sample before HPT and after HPT for 100 turns.

Each HPT-processed disc was cut into two halves along the radial axis using a wire cutting electrical discharge machine. The cross section of discs was examined using scanning electron microscopy (SEM) after mechanical polishing. For transmission electron microscopy (TEM) and scanning-transmission microscopy (STEM), foils were cut from the cross section of the discs at positions $3 \mathrm{~mm}$ from the center and were mechanically ground down to the thicknesses of $\sim 30 \mu \mathrm{m}$. Note that the samples were intentionally prepared at $3 \mathrm{~mm}$ from the disc center to avoid a low strained area at the disc center [6] and a dead metal zone at the disc edge [34]. TEM specimens were further thinned by ion milling at an operating voltage of $4 \mathrm{kV}$. Microstructure analyses were conducted using Philips CM200 and TECNAI G² F30 TEMs.

Elemental mapping was also conducted by the Gatan Imaging Filter Tridium attached on the TECNAI G ${ }^{2}$ F30 TEM and the jump ratio method was employed to obtain energy filtered maps. High-angle annular dark-field (HAADF) observations as well as energy dispersive X-ray spectroscopy (EDS) were carried out in the STEM mode with the condenser aperture of $100 \mu \mathrm{m}$ and nanoprobe mode using a beam size of $\sim 3 \mathrm{~nm}$. The chemical compositions and the dissolution of $\mathrm{Al}$ and $\mathrm{Cu}$ in each other were calculated by standard less method using a TIA software (TEM control software, Imaging and Analysis).

\section{Results}

Figure 2 shows back scattered electron (BSE) SEM images of the cross-sectional views for the samples after (a) 1 turn and (b-d) 100 turns. The brighter contrast corresponds to Cu-enriched 
regions because all images were taken by BSE. For the sample after 1 turn, as shown in (a), an Al layer is present between the two $\mathrm{Cu}$ layers and the boundaries between $\mathrm{Al}$ and $\mathrm{Cu}$ are clear. For the sample after 100 turns, as in (b), a fine layered structure is visible throughout the disc with a complex nature. The high magnification views show that the layered structure is curved irregularly at the center as in (c), and it is heavily distorted at the edge as in (d).

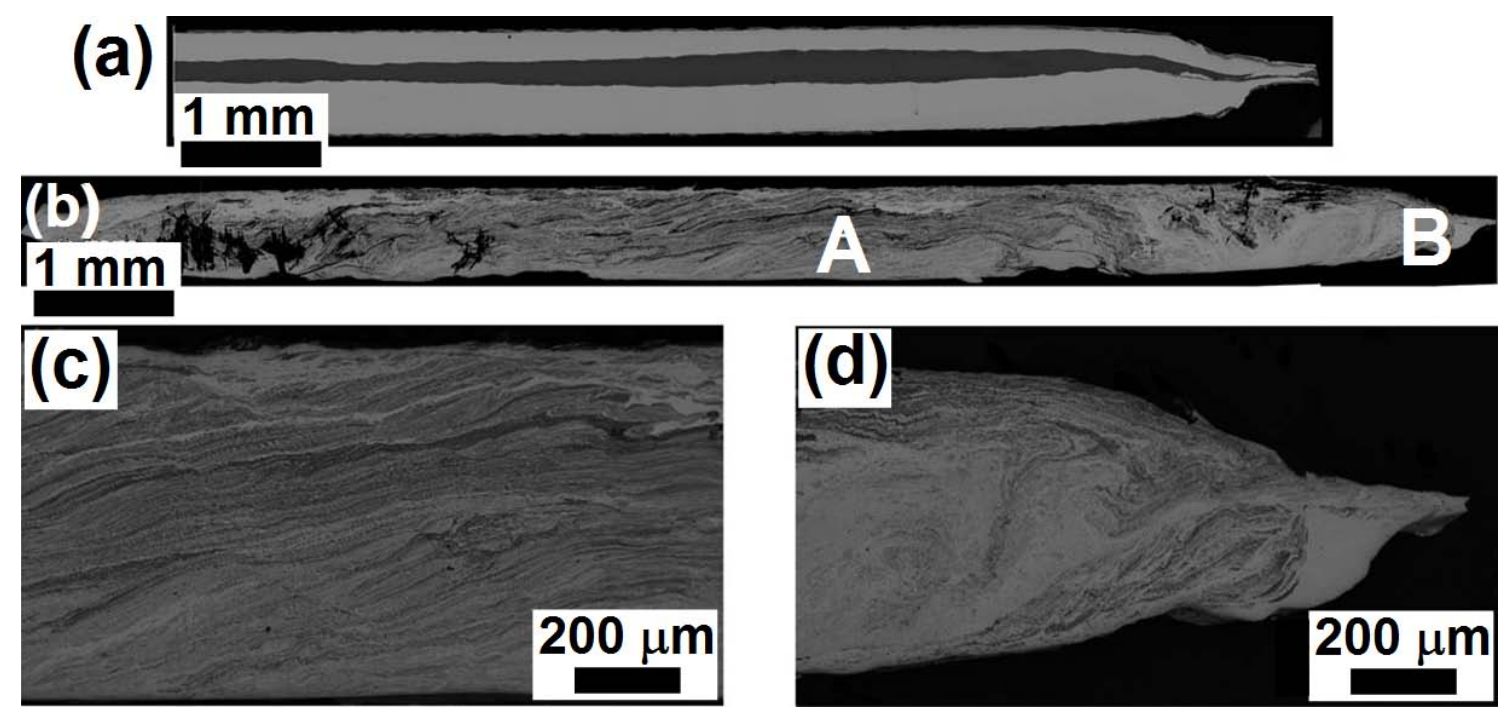

Figure 2. SEM images of Al-Cu samples processed by HPT for (a) 1 turn and (b-d) 100 turns, where (c) and (d) are magnified views of regions indicated by $\mathbf{A}$ and $\mathbf{B}$ in (b), respectively.

An XRD profile the sample after 100 turns is shown in Fig. 3. The analysis indicates the presence of an $\mathrm{Al}_{2} \mathrm{Cu}$ phase as well as $\mathrm{Al}$ and $\mathrm{Cu}$ phases. The solid-state reaction and formation of intermetallic phases by HPT was reported in the other Al-based systems such as Al-Mg, Al-Ni and Al-Ti [11,28,29].

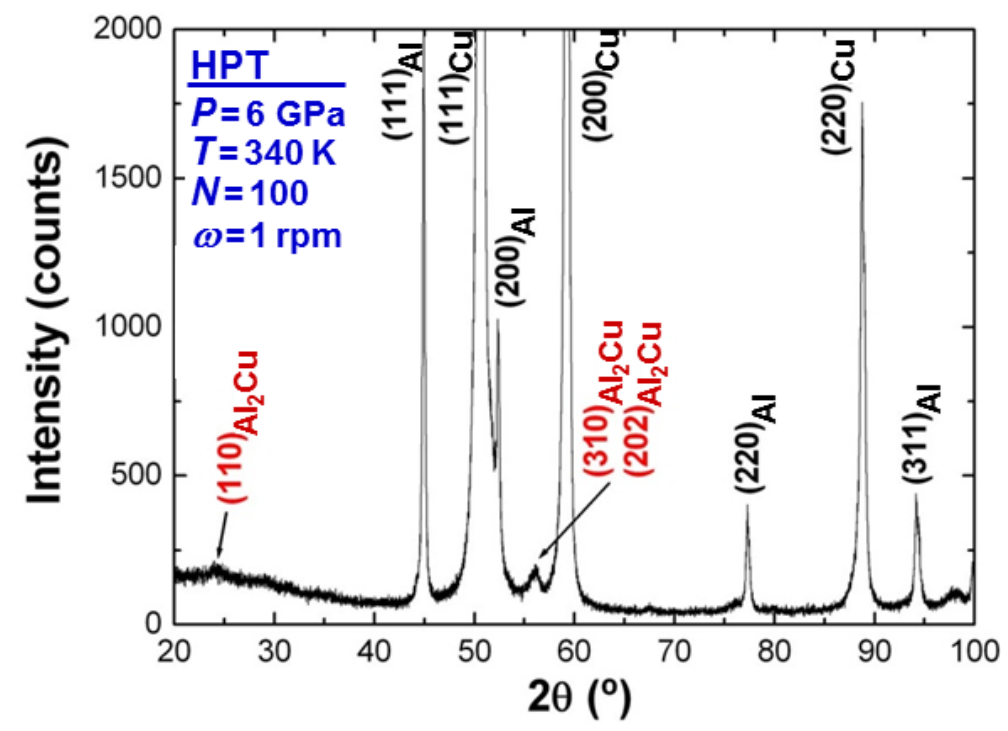

Figure 3. XRD profiles of Al-Cu sample processed by HPT for 100 turns. 
Figure 4 shows TEM micrographs and corresponding selected-area electron diffraction (SAED) patterns for the sample after 10 turns. The microstructure is inhomogeneous over a wide area and Al-enriched regions, as in (a), and Cu-enriched regions, as in (b), are present separately. Figure 4(a) shows that thin $\mathrm{Cu}$ layers with widths of less than $\sim 100 \mathrm{~nm}$ are present in the thick fine grained $\mathrm{Al}$ layers in the $\mathrm{Al}$-enriched regions. It is found that the $\mathrm{Al}$ layers consist of grains with the size of $\sim 500 \mathrm{~nm}$ which is much finer than the grain sizes of 1-2 $\mu \mathrm{m}$ reported in earlier experiments using ECAP [35] and HPT [36]. Few dislocations are visible in most of the grains in the Al layers with smooth and well defined grain boundaries. Figure 4(b) shows that microstructure in the Cu-enriched region has an ultrafine-grained structure with an average grain size of 300 $\mathrm{nm}$ with a high density of dislocations within grains. This microstructural feature is similar to the one reported in pure Cu subjected to ECAP [37] and HPT [38].

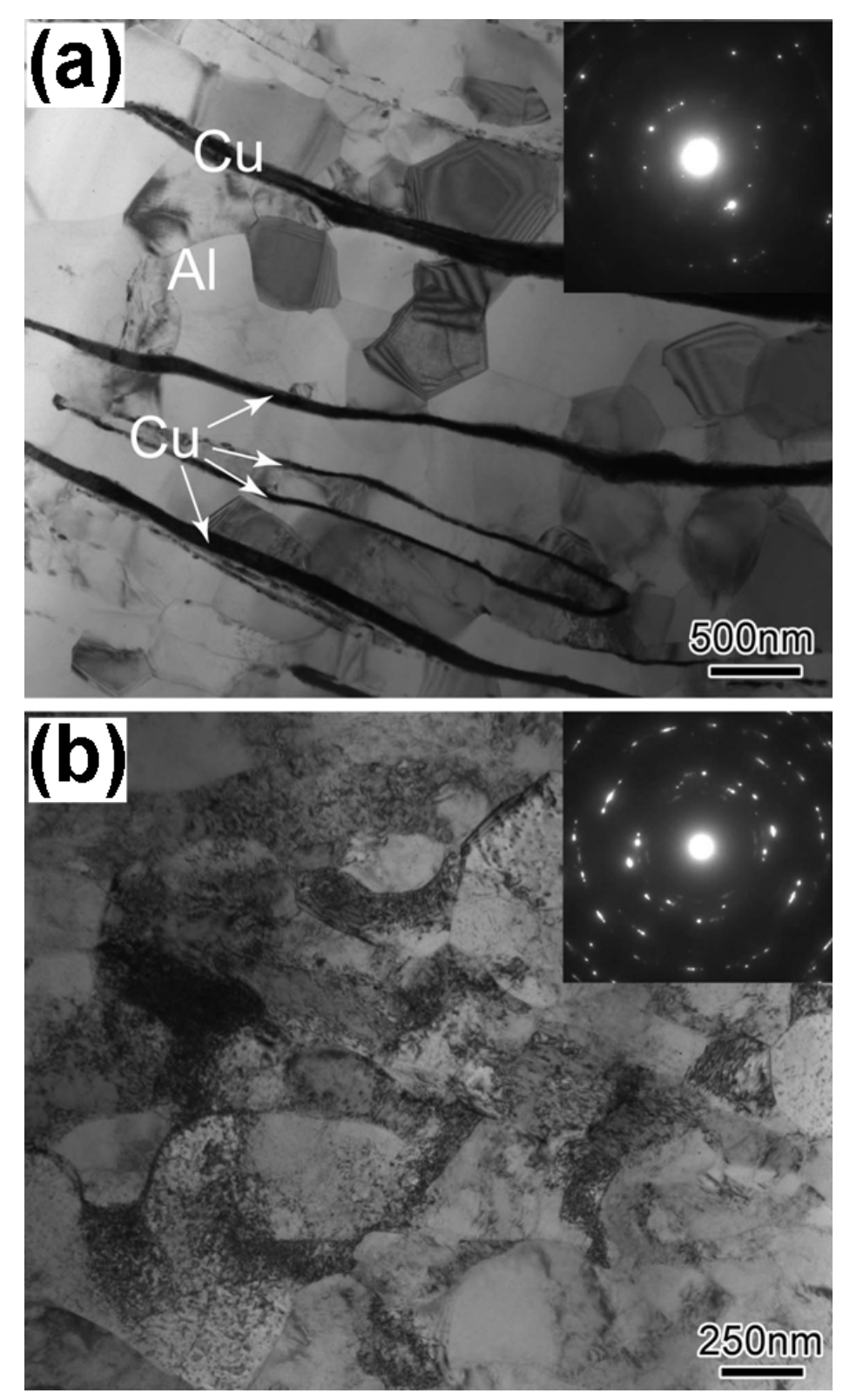

Figure 4. TEM micrographs and corresponding SAED patterns of Al-Cu sample processed by HPT for 10 turns, showing (a) layered structure in Al-enriched region and (b) refine-grained structure in Cu-enriched region. 
A TEM micrograph and a corresponding SAED pattern after 100 turns are shown in Fig. 5. It is apparent that a finer layered structure is developed when compared to that observed after 10 turns. The SAED analysis exhibits a ring pattern, indicating that the small grains are separated by high angles of misorientation without preferred crystallographic orientation.

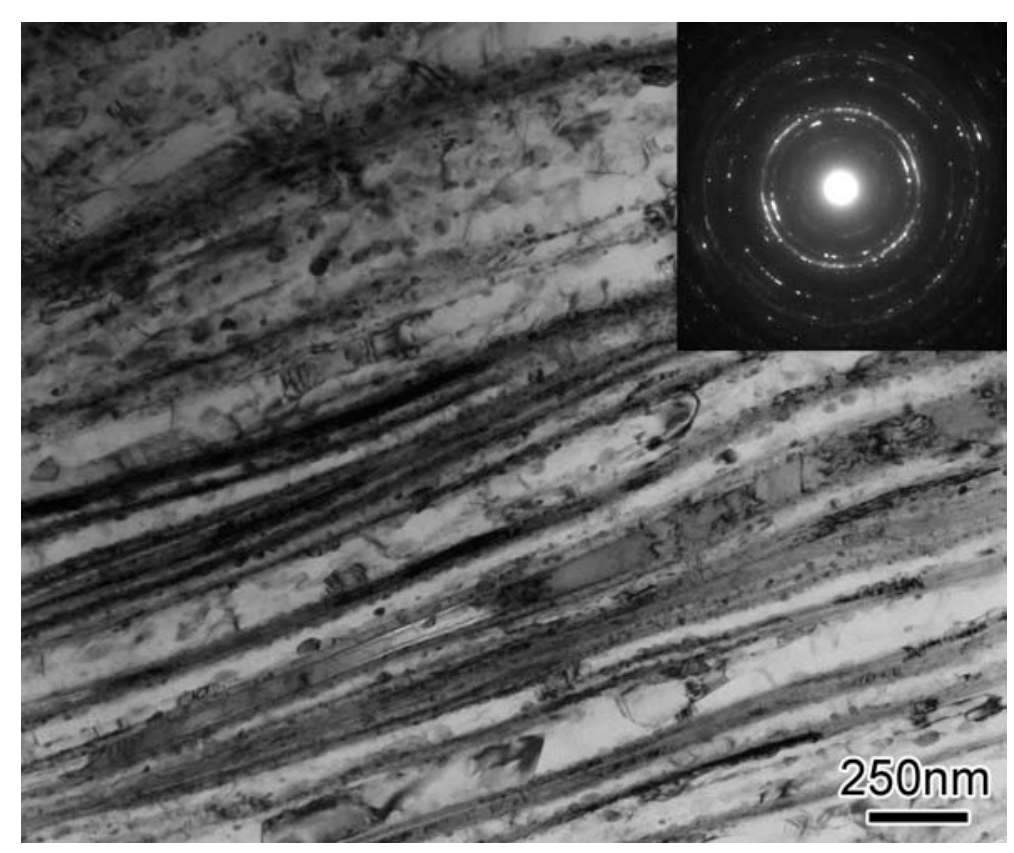

Figure 5. TEM micrograph and corresponding SAED pattern of Al-Cu sample processed by HPT for 100 turns.

In order to analyze the elemental distributions of $\mathrm{Al}$ and $\mathrm{Cu}$, energy filtered images were taken from the sample after 100 turns. A TEM bright-field image and the corresponding elemental maps of $\mathrm{Al}$ and $\mathrm{Cu}$ are shown in Figs. 6(a-c) from a representative area and in Figs. 6(d-e) from another representative area. Note that the sample is the same as the one used in Fig. 5, but the images were taken from different areas. Bright contrasts in the $\mathrm{Al}$ and $\mathrm{Cu}$ maps indicate the presence of Al-enriched and the $\mathrm{Cu}$-enriched regions. Figure 6(a-c) clearly shows that there are isolated $\mathrm{Cu}$-enriched regions with the size of $10-30 \mathrm{~nm}$ in the Al layers. Some elongated grains are also visible in the $\mathrm{Al}$ layer and it appears that the $\mathrm{Cu}$-enriched particles lie along the grain boundaries, as indicated by the arrows in Fig. 6(b).

Close inspection of the elemental maps in Fig. 6(e) reveals that there should be four distinctive regions associated with the difference in contrast. Regions $\mathbf{A}$ and $\mathbf{D}$ should be based on $\mathrm{Al}$ and $\mathrm{Cu}$, respectively, because they exhibit the brightest and darkest contrasts. Regions $\mathbf{B}$ and $\mathbf{C}$ can be intermetallic phases with Al-rich and Cu-rich compositions, respectively. The bright-field image in Fig. 6(d) shows that all regions consist of ultrafine grains with the sizes of 50 to $500 \mathrm{~nm}$, where the grain size tends to be smaller with increasing the fraction of $\mathrm{Cu}$. Micro-diffraction was carried out by positioning a focused beam on regions $\mathbf{B}$ and $\mathbf{C}$ to identify the phases. The diffraction patterns from regions $\mathbf{B}$ and $\mathbf{C}$ are shown in Fig. 7(a) and (b), respectively. It turns out that the diffraction pattern from region $\mathbf{B}$ is consistent with the [131] zone axis pattern of $\mathrm{Al}_{2} \mathrm{Cu}$ phase and 
the diffraction pattern from region $\mathbf{C}$ is consistent with the [113] zone axis pattern of $\mathrm{Al}_{4} \mathrm{Cu}_{9}$ phase. The calculated diffraction patterns for the $\mathrm{Al}_{2} \mathrm{Cu}$ and $\mathrm{Al}_{4} \mathrm{Cu}_{9}$ phases are shown in Figs. 7 (c) and (d), respectively, for comparison.
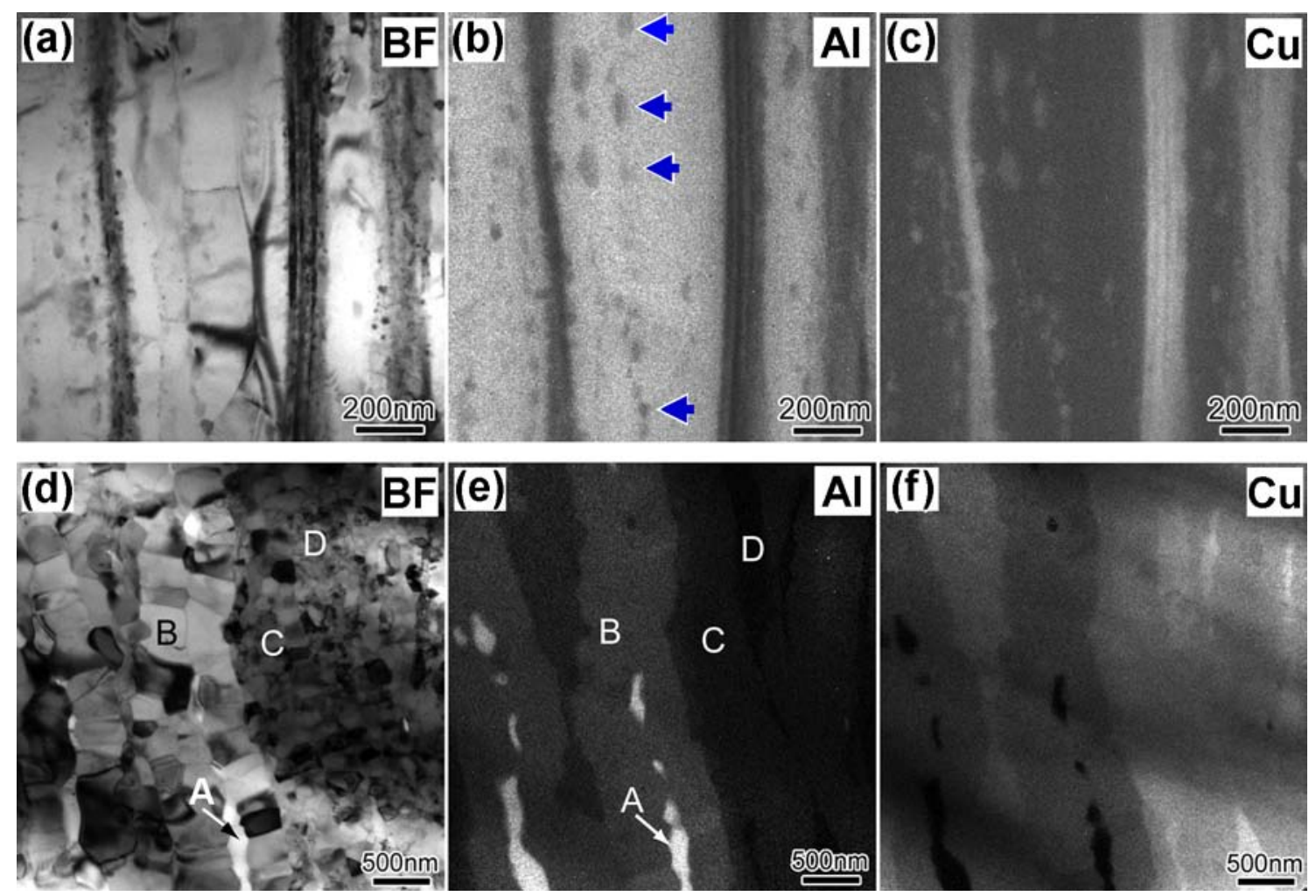

Figure 6. (a,d) Bright-field images and corresponding energy filtered elemental maps of (b,e) Al and (c,f) $\mathrm{Cu}$ in $\mathrm{Al}-\mathrm{Cu}$ sample processed by HPT for 100 turns.

Figure 8 shows an HAADF image of the sample processed by 100 turns, where brighter contrasts correspond to regions containing more $\mathrm{Cu}$. EDS analysis was then carried out to determine local chemical compositions by positioning a focused beam on the locations marked 1 to 7 in Fig. 8 . Table 1 documents the compositions obtained by the EDS analysis. Position 1 is the $\mathrm{Cu}$ phase containing $\sim 6$ at.\% of $\mathrm{Al}$ in the form of solid solution. Position 2 must be the $\mathrm{Al}_{4} \mathrm{Cu}_{9}$ phase which corresponds to region $\mathbf{C}$ in Fig. 7. Compositions of positions 3, 5 and 7 can be well matched with the one derived from the $\mathrm{Al}_{2} \mathrm{Cu}$ phase and therefore, corresponds to region $\mathbf{B}$ in Fig. 7. Position 4 is an supersaturated $\mathrm{Al}$ phase where $\mathrm{Cu}$ is dissolved by 2 at.\%. The composition at position 6 neither matches with the $\mathrm{Al}_{2} \mathrm{Cu}$ phase nor with the $\mathrm{Al}_{4} \mathrm{Cu}_{9}$ phase. Based on the $\mathrm{Al}-\mathrm{Cu}$ equilibrium phase diagram, position 6 is considered to correspond to the $\mathrm{AlCu}$ phase, although such a presence was not detected within the sensitivity limit of XRD and SAED analyses. The changes in the concentration of $\mathrm{Cu}$ from the $\mathrm{Cu}$-enriched region 1 to the Al-enriched region 4 in Fig. 8 clearly confirm that the reactions are controlled by atomic diffusion. 

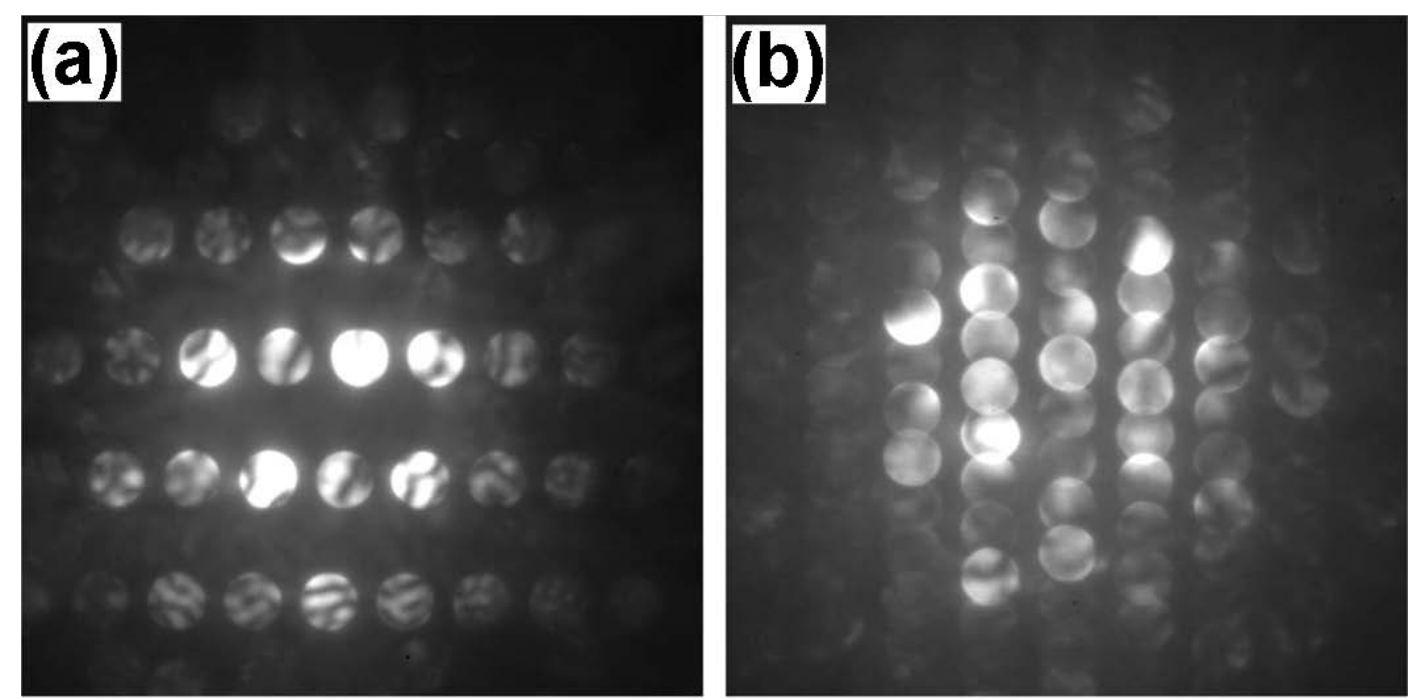

(c) $\mathrm{Al}_{2} \mathrm{Cu}[131]$

(d) $\mathrm{Al}_{4} \mathrm{Cu}_{9}[113]$

\begin{tabular}{|c|c|c|c|c|c|c|}
\hline 0000000 & 0 & & 0 & & 0 & \\
\hline & & 0 & ० & $\begin{array}{l}0 \\
0\end{array}$ & 0 & o \\
\hline$\bigcirc \bigcirc \bigcirc \underset{\mathbf{2} \overline{11}}{\bigcirc} \underset{\mathbf{4} \overline{1} \overline{1}}{\bigcirc}$ & $\begin{array}{l}0 \\
0\end{array}$ & 0 & $\begin{array}{l}0 \\
0\end{array}$ & 0 & $\begin{array}{l}0 \\
0\end{array}$ & ० \\
\hline$\bigcirc \bigcirc \bigcirc \bigcirc$ & & $\begin{array}{l}0 \\
0 \\
0\end{array}$ & $\begin{array}{l}\circ \\
\circ\end{array}$ & $\begin{array}{ll}0 \\
17 \\
0 \\
0\end{array}$ & & \\
\hline$\bigcirc \bigcirc \bigcirc \bigcirc \bigcirc \bigcirc$ & $\begin{array}{l}0 \\
0\end{array}$ & 0 & $\begin{array}{l}0 \\
0\end{array}$ & 0 & $0_{1}^{2}$ & $\overline{1}$ \\
\hline 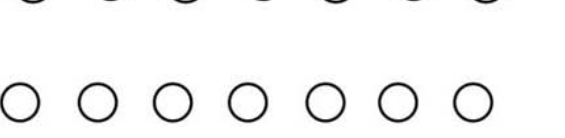 & & $\begin{array}{l}0 \\
0\end{array}$ & $\begin{array}{l}\circ \\
\circ\end{array}$ & $\begin{array}{l}0 \\
0\end{array}$ & $\begin{array}{l}0 \\
0\end{array}$ & $\begin{array}{l}\circ \\
0\end{array}$ \\
\hline
\end{tabular}

Figure 7. Micro-diffraction patterns obtained from grains (a) $\mathbf{B}$ and (b) $\mathbf{C}$ in Fig. 6, and simulated diffraction patterns of (c) $\mathrm{Al}_{2} \mathrm{Cu}$ in [131] direction and (d) $\mathrm{Al}_{4} \mathrm{Cu}_{9}$ in [113] direction.

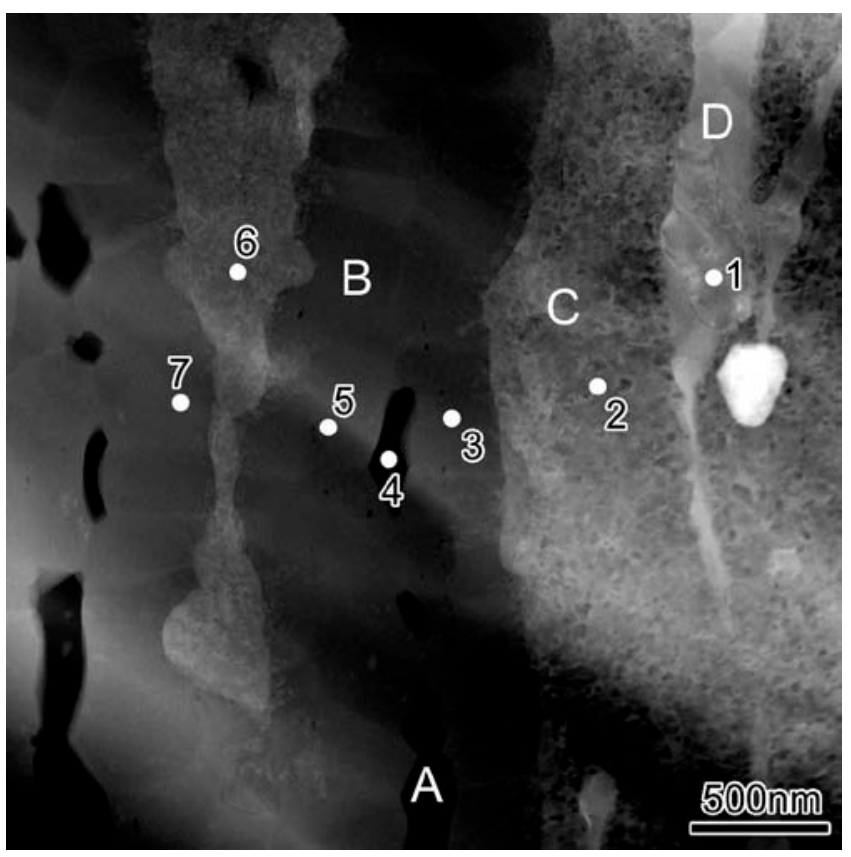

Figure 8. HAADF image for Al-Cu sample processed by HPT for 100 turns, including positions where the EDS analysis was conducted (EDS results are given in Table 1). 


\section{Discussion}

A question arises from the current investigation why the solid-state reaction and the formation of intermetallic phases are achieved by the HPT processing. It is reasonable that the atomic reaction may be enhanced by the following three factors during the HPT operation: (1) an increase in temperature due to plastic deformation and shear friction, (2) a reduction in atomic diffusion distance by microstructural refinement as discussed in an earlier report [28] and (3) an increase in the density of lattice defects such as vacancies, dislocations and grain boundaries. The relation between the diffusion distance, $x$, and diffusion coefficient, $D$, is generally described for a given period of time, $t$, as [39]

$$
x=\sqrt{D t}
$$

First, temperature was monitored during HPT operation using a thermocouple located at 10 $\mathrm{mm}$ above the bottom surface of the shallow hole on the upper anvil. The temperature gradually increased and reached $333 \mathrm{~K}$ after 20 turns and leveled off during further turns. This measurement indicates that the temperature of the sample does not exceed $340 \mathrm{~K}$, as discussed in details in Refs. [32,33]. Furthermore, differential scanning calorimetry measurements confirmed that there were no peaks appearing at least below the temperature of $473 \mathrm{~K}$ by thermal reactions. It is considered that $340 \mathrm{~K}$ should not be high enough to promote the solid state reaction as this temperature corresponds to $\sim 0.4 \mathrm{~T}_{\mathrm{m}}$ where $\mathrm{T}_{\mathrm{m}}$ is the melting temperature taken from the $\mathrm{Al}-33 \mathrm{wt} \% \mathrm{Cu}$ eutectic composition (the lowest melting point in the Al-Cu system). Therefore, although more quantitative evaluation will be given below, the solid-state reactions and the formation of the ordered phases cannot be attributed to the temperature rise during the HPT processing.

Second, as discussed in an earlier report [28], the grains are significantly elongated so that the widths of the elongated grains are considerably reduced by shear strain introduced by HPT processing. Considering the diffusion paths for solid-state reaction be equal to the widths of elongated grains and the time for diffusion be $6000 \mathrm{~s}$ corresponding to 100 turns in the HPT operation, the diffusion coefficients are estimated using Eq.(1) to be $D=10^{-19}-10^{-17} \mathrm{~m}^{2} / \mathrm{s}$ as documented in Table 1 together with the average path lengths for regions 1-7 in Fig. 8. For comparison, Table 1 also includes diffusion coefficients calculated from the following equation [39]

$$
D=D_{0} \exp \left(-\frac{Q+P V_{F}}{R T}\right)
$$

where $D_{0}$ is the frequency factor, $Q$ is the activation energy for diffusion, $P$ is the applied pressure, $V_{F}$ is the activation volume, $R$ is the gas constant and $T$ is the absolute temperature. The values for $D_{0}$ and $Q$ were taken from Ref. [40], and $P$ and $T$ were used as $6 \mathrm{GPa}$ and $340 \mathrm{~K}$, respectively. To examine the effects of pressure and temperature rise during the HPT operation, calculation was also attempted without application of pressure and at temperatures of 300 and $340 \mathrm{~K}$. For all selected compositions, $V_{F}$ was assumed to be $6.1 \times 10^{-6} \mathrm{~m}^{3} / \mathrm{mol}$, which is an average of $V_{F}$ for $\mathrm{Al}\left(6.5 \times 10^{-6}\right.$ $\left.\mathrm{m}^{3} / \mathrm{mol}\right)$ and $\mathrm{Cu}\left(5.7 \times 10^{-6} \mathrm{~m}^{3} / \mathrm{mol}\right)$ [41]. Referring to Table 1 , comparison shows that the estimated diffusion coefficients using Eq. (1) are $10^{12}-10^{22}$ times higher than those calculated using Eq. (2) for the lattice diffusion in the Al-Cu system under a pressure of $6 \mathrm{GPa}$ and at a temperature of $340 \mathrm{~K}$. It 
is noted that the temperature rise from $300 \mathrm{~K}$ to $340 \mathrm{~K}$ during HPT operation increases the diffusion coefficient by $\sim 10^{2}-10^{4}$ times but this is insufficient to account for the high diffusion coefficients obtained using Eq. (1). The application of the pressure, $6 \mathrm{GPa}$, for the HPT operation rather reduces the diffusion coefficient by $\sim 5 \times 10^{6}$ times.

Table 1. Chemical analyses for $\mathrm{Al}$ and $\mathrm{Cu}$ obtained by EDS analysis from selected regions in Fig. 9, diffusion path $(x)$ or average width of selected regions, and diffusion coefficients $(D)$ for selected regions calculated using Eqs. 1 and 2.

\begin{tabular}{cccccccc}
\hline & \multicolumn{7}{c}{ Regions in Fig. 8 } \\
\cline { 2 - 8 } & 1 & 2 & 3 & 4 & 5 & 6 & 7 \\
\hline $\mathrm{Al}$ (at.\%) & 6 & 30 & 64 & 98 & 63 & 47 & 60 \\
$\mathrm{Cu}($ at.\%) & 94 & 70 & 36 & 2 & 37 & 53 & 40 \\
\hline$x(\mathrm{~nm})$ & 150 & 600 & 300 & 100 & 450 & 480 & 430 \\
$D_{1}\left(\mathrm{~m}^{2} / \mathrm{s}\right)$ & $4 \times 10^{-18}$ & $6 \times 10^{-17}$ & $1 \times 10^{-17}$ & $2 \times 10^{-18}$ & $3 \times 10^{-17}$ & $4 \times 10^{-17}$ & $3 \times 10^{-17}$ \\
$D_{2}\left(\mathrm{~m}^{2} / \mathrm{s}\right)$ & $1 \times 10^{-39}$ & $3 \times 10^{-31}$ & $3 \times 10^{-30}$ & $2 \times 10^{-30}$ & $3 \times 10^{-30}$ & $7 \times 10^{-33}$ & $3 \times 10^{-30}$ \\
\hline$D_{1}$ obtained using Eq. (1). & & & & & \\
$D_{2}$ calculated using Eq. (2) with $P=6 \mathrm{GPa}, T=340 \mathrm{~K}$. & & &
\end{tabular}

Thus, the third factor, which is related to the population of lattice defects, must be very important to explain the difference. Earlier papers reported that the diffusivity can strongly be enhanced by SPD processing because of the presence of large fractions of high-angle grain boundaries formed during SPD [42-45]. It was also reported that the phase transformations are accelerated because of enhanced diffusivity in the SPD-processed materials [23,24,28,24]. Eq. (2) may be described in more detail with the form as $[39,40]$

$D=A C_{V} \exp \left(\frac{S_{M}}{R}\right) \exp \left(\frac{-H_{M}}{R T}\right)$

where $A$ is a constant depending on the attempted frequency, lattice parameter and crystallographic structure, $S_{M}$ and $H_{M}$ are the vacancy migration entropy and enthalpy, respectively, and $C_{V}$ is the vacancy concentration given by the following equation $[39,40]$

$C_{V}=\exp \left(\frac{S_{F}}{R}\right) \exp \left(\frac{-H_{F}}{R T}\right)=\exp \left(\frac{S_{F}}{R}\right) \exp \left(-\frac{E_{F}+P V_{F}}{R T}\right)$

where $S_{F}, H_{F}$ and $E_{F}$ are the vacancy formation entropy, enthalpy and energy, respectively. Thus, $D_{0}$ and $Q$ in Eq. (2) are represented as

$$
\begin{aligned}
& D 0=A \exp \left(\frac{S_{F}+S_{M}}{R}\right) \\
& Q=H_{M}+E_{F}
\end{aligned}
$$

It is reasonable that $E_{F}$ and $H_{M}$ should be affected significantly by the presence of lattice defects 
whereas the effect may be minimal on $S_{F}$ and $S_{M}$. Because many vacancies are expected to be present in the sample after HPT processing, $E_{F}$ should be lower than that in annealed state [46]. It is also considered that $H_{M}$ should be small [47-49] because a high density of lattice defects are available during the HPT processing [50]. It is well known that both dislocations and grain boundaries play roles as rapid diffusion paths. A precise estimation is difficult for $E_{F}$ and $H_{M}$ but, given $Q_{L}$ the activation energy for lattice diffusion, $Q$ may be selected as $1 / 2-2 / 3$ of $Q_{L}$ for dislocation-core diffusion (pipe diffusion) and grain boundary diffusion, and as $1 / 4-1 / 3$ of $Q_{L}$ for surface diffusion. It should be noted that the strain introduced during the HPT processing may influence the diffusivity via the changes of solute-vacancy binding energy [51], although this effect was not considered in this study.

Figure 9 plots the diffusion coefficients obtained using Eq. (1) for the corresponding $\mathrm{Cu}$ concentrations in regions 1-7 and compares with those calculated using different magnitudes of $Q$ through Eq. (2). It is shown that they are well comparable with those for surface diffusion. It is then concluded that the solid-state reaction and the formation of intermetallic phases are controlled by rapid diffusion due to the presence of many vacancies, dislocations and grain boundaries.

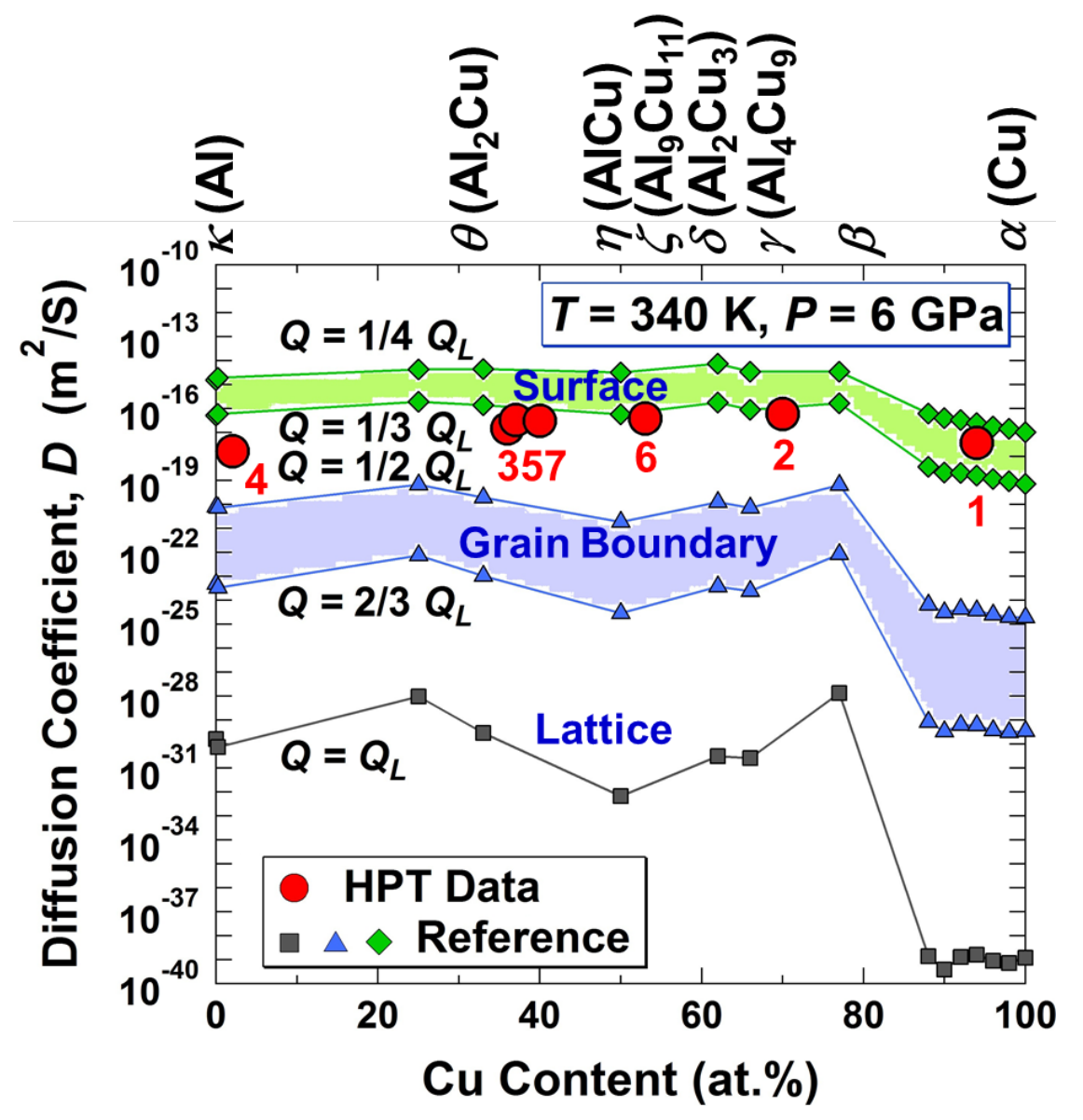

Figure 9. Estimated diffusion coefficients during HPT processing plotted against $\mathrm{Cu}$ content in comparison with the reference data calculated using three different activation energies such as lattice diffusion $\left(Q=Q_{L}\right)$, grain boundary diffusion $\left(Q=(1 / 2-2 / 3) Q_{L}\right)$ and surface diffusion $(Q=$ $\left.(1 / 4-1 / 3) Q_{L}\right)$. Diffusion coefficients obtained from Eq.(1) are labeled 1-7 corresponding to regions

1-7 in Fig.8. 


\section{Summary and conclusions}

HPT was applied to a bulk form of disc consisting of two separate half-discs of pure $\mathrm{Al}$ and pure $\mathrm{Cu}$. The following conclusions were obtained.

1. Alternating $\mathrm{Al}-\mathrm{Cu}$ layered structures with well-defined $\mathrm{Al} / \mathrm{Cu}$ interfaces are formed with a stacking sequence along the disc normal at an early stage of straining. With increasing the imposed strain (the number of turns), distorted lamellar Al-Cu structures are extended over the disc.

2. Processing by HPT promotes solid-state reaction of $\mathrm{Al}$ and $\mathrm{Cu}$ so that the formation of $\mathrm{Al}_{2} \mathrm{Cu}$, $\mathrm{AlCu}$ and $\mathrm{Al}_{4} \mathrm{Cu}_{9}$ intermetallic phases occurs as well as the dissolution of $\mathrm{Al}$ and $\mathrm{Cu}$ in each matrix.

3. The diffusion coefficients estimated from the formation of the ultrafine structures during HPT processing appear to be $10^{12}-10^{22}$ times higher than lattice diffusion and be comparable to surface diffusion.

4. The solid-state reaction and the formation of intermetallic phases are controlled by intense rapid diffusion due to the presence of many vacancies, dislocations and grain boundaries.

\section{Acknowledgments}

This work was supported in part by the Light Metals Educational Foundation of Japan, in part by a Grant-in-Aid for Scientific Research from the MEXT, Japan, in Innovative Areas "Bulk Nanostructured Metals" and in part by Kyushu University Interdisciplinary Programs in Education and Projects in Research Development (P\&P).

\section{References}

[1] Westbrook JH, Fleischer RL. Intermetallic Compounds, Principles and Practice, Vol. 1, Cichester: John Wiley \& Sons; 1995.

[2] Valiev RZ, Islamgaliev RK, Alexandrov IV. Prog Mater Sci 45;2000:103-189.

[3] Yoon EY, Lee DJ, Ahn DH, Lee ES, Kim HS. J Mater Sci 2012;47:7770-7776.

[4] Alexandrov IV, Zhu YT, Lowe TC, Islamgaliev RK, Valiev RZ. Metall Mater Trans A 1998;29:2253-2260.

[5] Zhilyaev AP, Gimazov AA, Raab GI, Langdon TG. Mater Sci Eng A 2008;486:123-128.

[6] Valiev RZ, Estrin Y, Horita Z, Langdon TG, Zehetbauer MJ, Zhu YT. JOM 2006;58(4):33-39.

[7] Murayam M, Horita Z, Hono K. Acta Mater 2001;49:21-29.

[8] Sha G, Wang YB, Lia XZ, Duan ZC, Ringer SP, Langdon TG. Acta Mater 2009;57:3123-3132.

[9] Bera S, Zuberova Z, Hellmig RJ, Estrin Y, Manna I. Phil Mag 2010;90:1465-1483.

[10] Ohsaki S, Kato S, Tsuji N, Ohkubo T, Hono K. Acta Mater 2007;55:2885-2895.

[11] Kaneko K, Hata T, Tokunaga T, Horita Z. Mater Trans 2009;50:76-81.

[12] Rajulapati KV, Scattergood RO, Murty KL, Horita Z, Langdon TG, Koch CC. Metall Mater Trans A 2008;39:2528-2534.

[13] Edalati K, Toh S, Iwaoka H, Horita Z. Acta Mater 2012;60:3885-3893.

[14] Tian YZ, Zhang JJ, Wu SD, Zhanng ZF, Kawasaki M, Langdon TG. Acta Mater 2012;60:269-281.

[15] Sauvage X, Wetscher F, Pareige P. Acta Mater 2005;53:2127-2135.

[16] Sauvage X, Jessner P, Vurpillot F, Pippan R, Scripta Mater 2008;58:1125-1128.

[17] Nishihata S, Suehiro K, Arita M, Masuda M, Horita Z. Adv Eng Mater 2010;12:793-797. 
[18] Sabirov I, Kolednik O, Pippan R. Metall Mater Trans A 2005;36:2861-2870.

[19] Oh-ishi K, Horita Z, Smith DJ, Valiev RZ, Nemoto M, Langdon TG. J Mater Res 1999;14:4200-4207.

[20] Zhilyaev AP, Langdon TG. Prog Mater Sci 2008;53:893-979.

[21] Wei Q, Zhang HT, Schuster BE, Ramesh KT, Valiev RZ, Kecskes LJ, Dowding RJ, Magness L, Cho K. Acta Mater 2006;54:4079-4089.

[22] Ciuca O, Tsuchiya K, Yokohama Y, Todaka Y, Ummemoto M. Mater Trans 2010;51:14-22.

[23] Perez-Prado MT, Gimazov AA, Ruano OA, Kassner ME, Zhilyaev AP. Scripta Mater 2008;58:219-222.

[24] Straumal BB, Mazilkin AA, Baretzky B, Schutz G, Rabkin E, Valiev RZ. Mater Trans 2012;53:63-71.

[25] Sun YF, Fuji H, Nakamura T, Tsuji N, Todaka D, Umemoto M. Scripta Mater 2011;65:489-492.

[26] Revesz A, Hober S, Labar JL, Zhilyaev AP, Kovacs Z. J Appl Phys 2006;100:103522.

[27] Huang JY, Zhu YT, Liao XZ, Valiev RZ. Phil Mag Lett 2004;84:183-190.

[28] Edalati K, Toh S, Watanabe M, Horita Z. Scripta Mater 2012;66:386-389.

[29] Edalati K, Toh S, Iwaoka H, Watanabe M, Horita Z, Kashioka D, Kishida K, Inui H. Scripta Mater 2012;67:814-817.

[30] Long BD, Umemoto M, Todaka Y, Othman R, Zuhailawati H. Mater Sci Eng A 2011;528:150-1756.

[31] Edalati K, Horita Z, Mine Y. Mater Sci Eng A 2010;527:2136-2141.

[32] Edalati K, Miresmaeili R, Horita Z, Kanayama H, Pippan R. Mater Sci Eng A 2011;528:7301-7305.

[33] Figueiredo RB, Pereira PHR, Aguilar MTP, Celtin PR, Langdon TG. Acta Mater 2012;60:3190-3198.

[34] Lee DJ, Yoon EY, Park LJ, Kim HS. Scripta Mater 2012;67:384-387.

[35] Iwahashi Y, Horita Z, Nemoto M, Langdon TG. Acta Mater 1998;46:3317-3331.

[36] Xu C, Horita Z, Langdon TG. Acta Mater 2007;55:203-212.

[37] Komura S, Horita Z, Nemoto M, Langdon TG. J Mater Res 1999;14:4044-4050.

[38] Edalati K, Fujioka T, Horita Z. Mater Sci Eng A 2008;497:168-173.

[39] Shewmon P. Diffusion in Solids, second ed. Pennsylvania: The Minerals, Metals \& Materials Society; 1989.

[40] Mehrer H. Numerical Data and Functional Relationships in Science and Technology, Diffusion in Solid Metals and Alloys, Vol. 26, Berlin: Springer-Verleg; 1990.

[41] Kraftmakher Y. Phys Rep 1998;299:79-188.

[42] Fujita T, Horita Z, Langdon TG. Phil Mag A 2002;82:2249-2262.

[43] Fujita T, Horita Z, Langdon TG. Mater Sci Eng A 2004;241:241-250.

[44] Divinski SV, Ribbe J, Baither D, Schmitz G, Reglitz G, Rosner H, Sato K, Estrin Y, Wilde G. Acta Mater 2009;57:5706-5717.

[45] Divinski SV, Reglitz G, Rosner H, Estrin Y, Wilde G. Acta Mater 2011;59:1974-1985.

[46] Gavini V. Proc Roy Soc A 2009;465:3239-3266.

[47] Koehler JS. Phys Rev 1969;181:1015-1019.

[49] Sato K, Yoshiie T, Satoh Y, Xu Q. Mater Trans 2004;45:833-838.

[50] Setman D, Schafler E, Korznikova E, Zehetbauer MJ. Mater Sci Eng A 2008;493:116-122.

[51] Wurschum R, Oberdorfer B, Steyskal EM, Sprengel W, Puff W, Pikart P, Hugenschmidt C, Pippan R. Physica B 2012;407:2670-2675.

[52] Wolverton C. Acta Mater 2007;55:5867-5872. 